\title{
Variation in floral scent compounds recognized by honeybees in Brassicaceae crop species
}

\author{
Kiwa Kobayashi' ${ }^{1)}$, Miyako Arai' ${ }^{1)}$, Atsushi Tanaka', Shigeru Matsuyama'), Hiroshi Honda1) \\ and Ryo Ohsawa*1) \\ 1) Institute of Life and Environmental Sciences, University of Tsukuba, 1-1-1 Tennodai, Tsukuba, Ibaraki 305-8572, Japan \\ 2) Tohoku Seed Company, 1625 Nishihara, Himuro, Utsunomiya, Tochigi 321-3232, Japan
}

\begin{abstract}
Floral scent attracts pollinators. We investigated the floral scent compounds recognized by pollinators in six Brassica crop species, including allogamous species with different genomes and autogamous species with two parental genomes and radish (Raphanus sativus). Biologically active compounds recognized by honeybees were screened from all floral compounds by combined gas chromatography-electroantennogram analysis and their profiles were determined by gas chromatography-mass spectrometry. Fourteen of the 52 compounds were active. All accessions had more than two active compounds, but the compounds greatly differed between the two genera. On the basis of similarities in whether active compounds were presence or absence, their amount and their composition ratio, we divided the Brassica accessions into three to five groups by cluster analyses. Most groups were composed of a mixture of allogamous and autogamous species sharing same genome, indicating that the variation depended on genome, not species. These results suggest that all species require pollinator visits for reproduction, despite their different reproductive systems. However, the inter-genus and intra-specific variations shown by the multiple groups within a species might cause different visitation frequencies by pollinators between genera and among accessions within a species, resulting in insufficient seed production in some accessions or species.
\end{abstract}

Key Words: Brassicaceae, floral scent compounds, gas chromatography-electroantennogram detection, honeybees, pollinator requirement, reproductive system, seed production.

\section{Introduction}

The genera Brassica and Raphanus belong to the Brassicaceae (Warwick et al. 2006) and contain many agriculturally important species (Pratap and Gupta 2009), including turnip (Brassica rapa), cabbage (Brassica oleracea), mustard (Brassica nigra), rapeseed (Brassica napus) and radish (Raphanus sativus). Among the Brassica crop species, B. rapa (AA, $2 n=20)$, B. nigra (BB, $2 n=16)$ and $B$. oleracea $(\mathrm{CC}, 2 n=18)$ are diploid species with different genomes, whereas Brassica juncea (AABB, $2 n=36$ ), Brassica napus (AACC, $2 n=38$ ) and Brassica carinata (BBCC, $2 n=34$ ) are amphidiploid species that contain both parental genomes as a result of hybridization among the diploid species (Tsunoda et al. 1980). The reproductive systems of these species are allogamous; the diploid species are selfincompatible and the amphidiploid species have incomplete autogamy combined with self-compatibility (Free 1970). $R$. sativus is also allogamous owing to self-incompatibility.

Owing to these reproductive characteristics, the diploid

Communicated by M. Hirai

Received March 9, 2012. Accepted July 26, 2012.

*Corresponding author (e-mail: osawa.ryo.gt@u.tsukuba.ac.jp) species need insect pollinators in order to set seed. On the other hand, although the self-compatible amphidiploid species are believed to be capable of setting seed without insect pollinators (Free and Spencer-Booth 1963, Free and Nuttall 1968), they produce more seed with them (Jenkinson and Glynne-Jones 1953, Ohsawa and Namai 1987). On this basis, we predict that amphidiploid species will have a diversity of pollinator requirements and that insect pollination may promise higher seed set in all diploid and amphidiploid species. If so, all species would possess characteristics that attract insect pollinators and might show narrow inter-specific differences in their pollinator requirements.

Brassicaceae species are generalist plants and various insects visit the flowers as pollinators. However, a honeybee is one of the main pollinator (Jenkinson and Glynne-Jones 1953, Ohsawa and Namai 1987) and is frequently used for commercial seed production of the Brassicaceae crop species. It sometimes neglects radishes and visit other neighboring crops such as Brassica species, which secrete more nectar (Free 1970). In fields where $F_{1}$ seed of cruciferous crops is produced, it often discriminates between the two parents and favors one over the other (Kobayashi et al. 2010, Niikura 2007, Tanaka et al. 2007). Such different visitation frequencies of honeybees might be due to inter-genus and 
intra-specific variation in pollinator requirements, resulting in insufficient seed production.

Floral scent is an important characteristic in attracting pollinators (Chittka and Raine 2006) and scents can be complex because they contain a wide variety of volatile compounds (e.g., Evans and Allen-Williams 1992, Jakobsen et al. 1994, Robertson 1993, Tollsten and Bergström 1988). Although various compounds will be present in Brassica species and in $R$. sativus, insect pollinators may not necessarily respond to all of them (Andersson and Dobson 2003, Huber et al. 2005). In addition, they may respond as signals in at least three ways: according to the presence or absence of a specific compound, the emitted amount of a specific compound, and the composition (ratios) of multiple compounds in the scent (Barth 1997, Huber et al. 2005, Omura et al. 1999).

In this study, we identified the qualitative and quantitative variations in the floral scent compounds that were recognized by honeybees in the six Brassica species and radish and evaluated the diversity of floral scents from the viewpoint of species' pollinator requirements.

\section{Materials and Methods}

\section{Plant materials}

To examine the variation in floral scent among the seven species, we selected four to six cultivars or lines of each Brassica species and two of $R$. sativus on the basis of differences in the subspecies and their origins. We used a total of 32 accessions (Table 1 ). The accessions were provided by Tohoku University (Sendai, Japan), Utsunomiya University and the Tohoku Seed Company (Utsunomiya, Japan) and the NIAS Genebank (Tsukuba, Japan).

\section{Collection of flower volatiles}

Generally, floral volatiles could be influenced by both biotic and abiotic factors in the field conditions. To minimize these influences, the cultivation condition and sampling

Table 1. The 32 cultivars or lines of six Brassica and one Raphanus species used to evaluate the variation in floral scent

\begin{tabular}{|c|c|c|c|c|}
\hline Species (Genome) & Line No. & Subspecies/Cultivar name (Line name) & Country & Distribution facility $^{c}$ \\
\hline \multirow[t]{4}{*}{ B. rapa $(\mathrm{AA})$} & 1 & chinensis/Yukina (C-333) & Japan & $\mathrm{A}$ \\
\hline & 2 & rapa/Oguni-kabu (C-470) & Japan & $\mathrm{A}$ \\
\hline & 3 & toria/ $--^{b}(\mathrm{C}-504)$ & India & A \\
\hline & $4^{a}$ & japonica/Sensuzikyomizuna & Japan & $\mathrm{B}$ \\
\hline \multirow[t]{5}{*}{ B. nigra $(\mathrm{BB})$} & $5^{a}$ & -/Poimt rayes $(\mathrm{Ni}-135)$ & USA & A \\
\hline & 6 & -/Nlcaslo (Ni-136) & USA & A \\
\hline & $7^{a}$ & $-/-(\mathrm{Ni}-138)$ & Algeria & A \\
\hline & 8 & $-/-(\mathrm{Ni}-141)$ & USA & A \\
\hline & 9 & $-/-(\mathrm{Ni}-142)$ & USA & A \\
\hline \multirow[t]{6}{*}{ B. oleracea $(\mathrm{CC})$} & $10^{a}$ & $-/-(\mathrm{O}-165)$ & Morocco & A \\
\hline & $11^{a}$ & alboglabral-(O-201) & Russia & A \\
\hline & 12 & acephala/Murasakihabotan & Japan & B \\
\hline & $13^{a}$ & botrytis/Ajiboshi & Japan & $\mathrm{D}$ \\
\hline & $14^{a}$ & capitata/Siraho & Japan & $\mathrm{D}$ \\
\hline & 15 & italica/Ryokuseki & Japan & $\mathrm{D}$ \\
\hline \multirow[t]{5}{*}{ B. juncea (AABB) } & $16^{a}$ & -/Snst. IC 10956. (J-114) & India & A \\
\hline & 17 & -/Tri 83-1508 (J-473) & Canada & $\mathrm{A}$ \\
\hline & 18 & -/Karashina & Japan & $\mathrm{C}$ \\
\hline & 19 & -/Kikarashi & Japan & $\mathrm{C}$ \\
\hline & 20 & -/Seisai & China & $\mathrm{C}$ \\
\hline \multirow[t]{4}{*}{ B. napus (AACC) } & $21^{a}$ & -/Isuzunatane (N-137) & Japan & A \\
\hline & 22 & -/Aomori No.1 & Japan & $\mathrm{C}$ \\
\hline & 23 & $-/$ Karafuto & Russia & $\mathrm{C}$ \\
\hline & $24^{a}$ & -/Taisetsunatane & Japan & $\mathrm{C}$ \\
\hline \multirow[t]{6}{*}{ B. carinata $(\mathrm{BBCC})$} & 25 & -/Gommen-Zerh (Ca-112) & Ethiopia & A \\
\hline & $26^{a}$ & -/Long stalked cabbage (Ca-115) & Ethiopia & A \\
\hline & 27 & $-/-(\mathrm{Ca}-118)$ & Spain & A \\
\hline & 28 & -/Awasa Population & Ethiopia & $\mathrm{C}$ \\
\hline & 29 & -/Addis Abeba local 2-1 & Ethiopia & $\mathrm{C}$ \\
\hline & $30^{a}$ & -/Debae Zeit local & Ethiopia & $\mathrm{C}$ \\
\hline \multirow[t]{2}{*}{ R. sativus (RR) } & $31^{\mathrm{a}}$ & -/Riso & Japan & $\mathrm{B}$ \\
\hline & 32 & -/Syogoin & Japan & $\mathrm{B}$ \\
\hline
\end{tabular}

${ }^{a}$ Cultivars or lines used in the GC-EAD analysis.

${ }^{b}$ No information.

${ }^{c}$ A: Tohoku Univ. B: Utsunomiya Univ. C: NIAS. D: Tohoku Seed Co. 
stage were uniformed in the all plants. The plants were sown in separate cells of $4-\mathrm{cm} \times 4-\mathrm{cm}$ trays filled with a commercial soil ("Tsuchitaro"; Sumitomo, Tokyo, Japan) in September (B. oleracea) and late December (all others) 2006. After the seedlings had developed true leaves, one to five individuals per accession were transplanted into an each $24-\mathrm{cm}$ plastic pot. All plants were grown in a greenhouse at the Agriculture and Forestry Research Center, University of Tsukuba (Ibaraki, Japan). During the full bloom period of each plant (2 to 6 weeks after flowering began), about 20 inflorescences were randomly sampled from each plant and after counting the total number of opened flowers, we placed the inflorescences into $150 \mathrm{~mL}$ of distilled water in a small vial, which was then placed immediately in a glass aeration chamber $(7 \mathrm{~L})$. Charcoal-filtered air was pulled into the chamber through a lateral inlet via Tygon tubing (SaintGoban K.K., Courbevoie, France) by a diaphragm pump (MP- 5300 , Shibata, Tokyo, Japan). The air and any headspace volatiles from the flowers were passed through an absorbent cartridge (ORBO 42-small; Supelco, Bellefonte, PA, USA) for $48 \mathrm{~h}$ at $700 \mathrm{~mL} / \mathrm{min}$ at room temperature. Trapped volatiles were eluted from the absorbent by solvent desorption at room temperature in $2 \mathrm{~mL}$ of redistilled hexane and the collected solution was concentrated to $20 \mu \mathrm{L}$ under a nitrogen gas stream. The volatile floral extracts were stored in glass vials at $-20^{\circ} \mathrm{C}$ until use.

\section{Analysis of the volatiles}

We performed gas chromatography-mass spectrometry (GC-MS) analyses using a Hewlett-Packard 5972 mass spectrometer (Agilent Technologies, Santa Clara, CA, USA) coupled with an HP 5890 Series II gas chromatograph (GC) equipped with an HP-5MS column $(30 \mathrm{~m} \times 0.32 \mathrm{~mm}$ ID, film thickness $0.25 \mu \mathrm{m}$; Agilent Technologies). The oven temperature was held for $2 \mathrm{~min}$ at $50^{\circ} \mathrm{C}$ and increased to $250^{\circ} \mathrm{C}$ at $5^{\circ} \mathrm{C} / \mathrm{min}$ and was then held at $250^{\circ} \mathrm{C}$ for $15 \mathrm{~min}$. We injected $1 \mu \mathrm{L}$ of each sample in splitless mode at $250^{\circ} \mathrm{C}$ using helium as the carrier gas. The temperature of the interface was maintained at $280^{\circ} \mathrm{C}$. Electron ionization (EI) mass spectra of the floral scent components were obtained at an ionization voltage of $70 \mathrm{eV}$ and an ion source temperature of $280^{\circ} \mathrm{C}$. The floral scent components were identified against the Wiley Mass Spectral Data Library (7th Edition; WileyBlackwell, Hoboken, NJ, USA).

\section{Combined GC-electroantennogram analysis}

Floral scent extracts were subjected to coupled gas chromatography-electroantennogram detection (GC-EAD) analyses with worker honeybees to detect biologically active components (Fig. 1). The GC-EAD analyses (Struble and Arn 1984) were conducted with each two samples of headspace volatiles from 13 accessions of cruciferous plants to cover all the compounds detected in this study (Table 1). GC-EAD analysis was conducted using an HP 6890 PLUS GC (Agilent Technologies) equipped with a $30-\mathrm{m} \times 0.25$ mm capillary column (HP-1MS, Agilent Technologies). We injected $1 \mu \mathrm{L}$ of each sample in splitless mode at $250^{\circ} \mathrm{C}$ using helium as the carrier gas. The oven temperature was maintained at $40^{\circ} \mathrm{C}$ for $1 \mathrm{~min}$ and programmed to rise at $10^{\circ} \mathrm{C} / \mathrm{min}$ to $300^{\circ} \mathrm{C}$ and then held steady for $1 \mathrm{~min}$. The effluent from the column was split and divided at a ratio of $1: 1$ between a flame ionization detector (FID) and an EAD apparatus (described below), the latter passing through a heated $\left(230^{\circ} \mathrm{C}\right)$ transfer line into a stream of humidified air $\left(300 \mathrm{~mL} / \mathrm{min}\right.$ at $\left.23^{\circ} \mathrm{C}\right)$ directed at the antennal preparation in a glass container. In each time, 20 ppm of both 2-Heptanone and n-Heptaldehyde were used as internal standard.

Honeybee (Apis mellifera) workers were collected from a

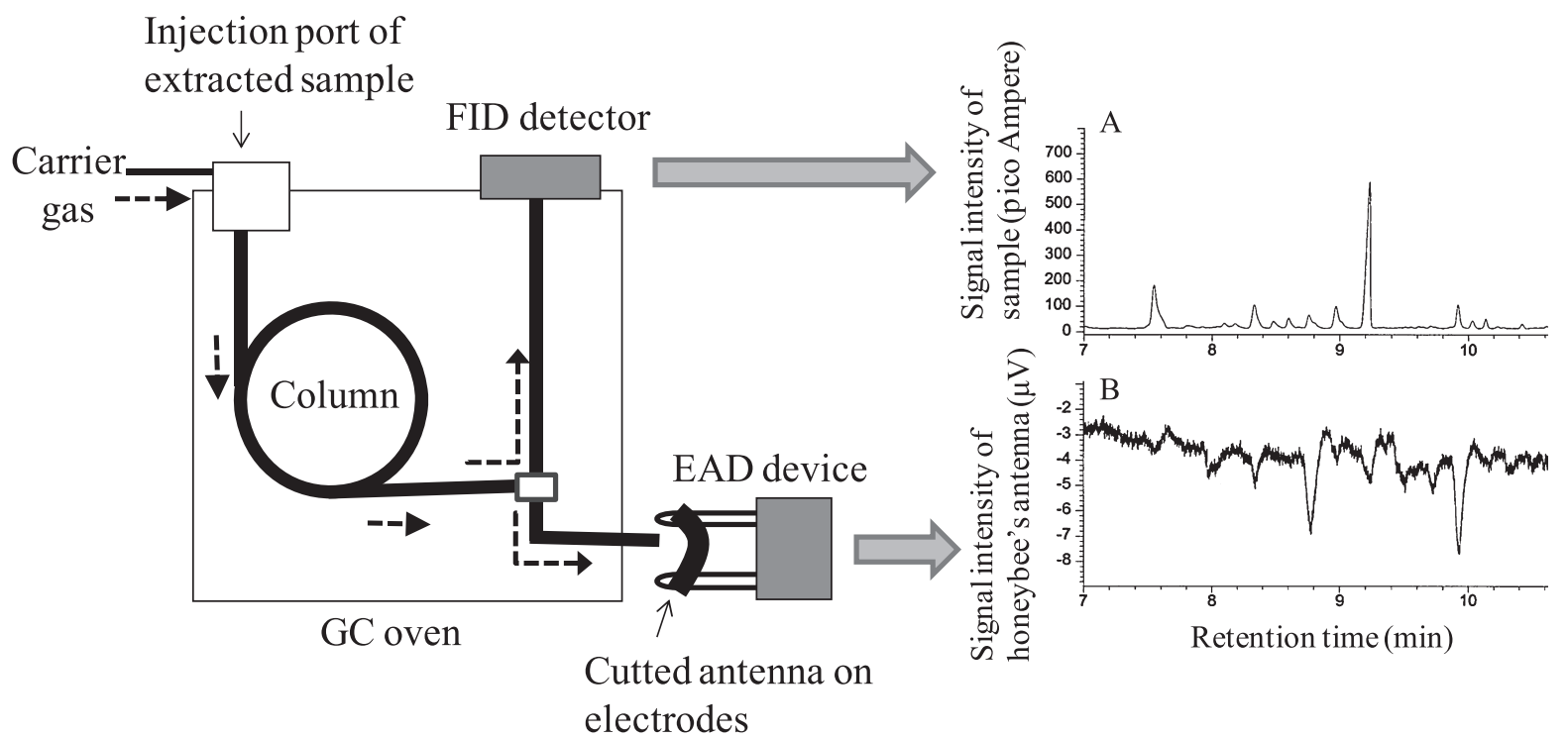

Fig. 1. Diagram of combined GC-EAD analysis. Dashed arrows mean the flow of carrier gas. Gas chromatogram of extracted sample (A) and oscillograph of honeybee's antenna (B) were obtained from FID detector and EAD device, respectively. 

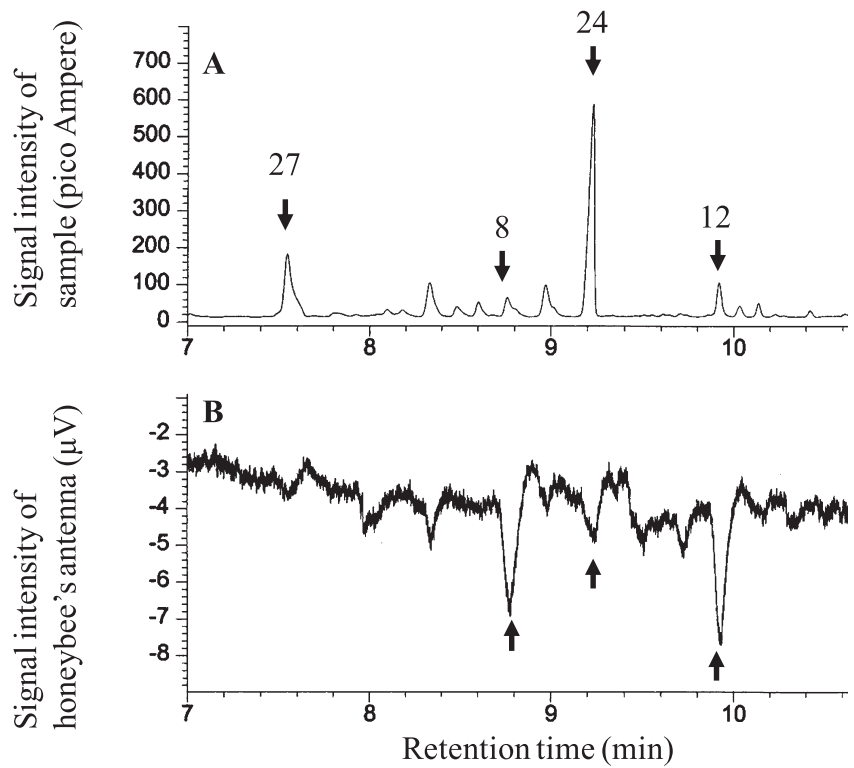

Fig. 2. Gas chromatogram (A) and oscillograph (B) using long stalked cabbage (Ca-115) sample. Numbers in (A) mean the corresponding compound number in Table 2. Each compound pointed by an arrow in (B) shows high peak, considering as an active compound.

colony hive at the University of Tsukuba from 10:00 to 12:00 on clear days in October and November 2007. One antenna per insect was cut off at the base with a tapered forceps and bridged between two silver electrodes of the EAD device sitting in a saline solution (Ai et al. 1995). The FID and EAD signals were recorded simultaneously. We considered compounds with a clearly higher peak than the usual level in an oscillograph to be compounds capable of eliciting physiological activity in a honeybee antenna (i.e., to be active compounds, see also Fig. 2). The antenna was replaced when the peak heights to the internal standards weakened. Synthetic compounds were used to confirm the retention times in some active compounds. In addition, different columns were used for GC-MS (HP-5) and GC-EAD (HP-1), leading to possibility of misidentification in volatile compounds. To ensure consistency between both analyses, GC-MS analyses using a MS-600 (JEOL, Tokyo, Japan) coupled with an HP $6890 \mathrm{~N}$ GC equipped with an HP-1MS column also conducted in some floral extracts. The column temperature, carrier gas and its flow rate were same with the $\mathrm{GC}-\mathrm{EAD}$ analysis and temperature of the inlet and interface was maintained at $280^{\circ} \mathrm{C}$. EI mass spectra were obtained at an ionization voltage of $70 \mathrm{eV}$.

\section{Data analysis}

In each sample, the detected active compounds were described in three ways: the presence or absence, the amount that was present, and the percentage composition of the active compounds. The presence or absence of each compound was based on the outcome of the GC-MS analysis and was scored as 1 or 0 . The amount of each compound was determined by dividing the peak area of the total ion chromato- gram, which was calculated by pico ampere $\times$ full width at half maximum of the compound in the GC-MS chromatogram, by the total number of opened flowers used to collect the scent. The percentage composition of each compound was calculated as \{peak area of each compound/sum of peak area of all active compounds $\} \times 100$. For this calculation, we used arithmetic averages.

Most compounds were specific to only some of the species or accessions, resulting in an unbalanced dataset with many 0 values (absence) in each evaluation. Therefore, to evaluate the overall variation without bias from these results, we performed cluster analysis using Ward's method in each parameter. To avoid disrupting the numerical relationships among the compounds, we defined the distance between clusters using the Euclidean distance without standardization of the variance for each compound. In the resulting dendrogram, similarity levels (Sneath and Sokal 1994) for a cluster with zero distance and for a final cluster with the maximum distance were defined as $100 \%$ and $0 \%$, respectively. Each group was then separated at the 50\% similarity level (i.e., at half of the maximum distance) and characterized by the average among the accessions belonging to the same group. For statistical analysis, we used version 4.0 of JMP software (SAS Institute Inc., Cary, NC, USA).

\section{Results}

We detected a total of 52 compounds, including aliphatics, aromatics, isoprenoids (irregular terpenes, monoterpenes and sesquiterpenes) and nitrogen-containing compounds in the floral scents of the seven species (Table 2). The largest difference was found between the Brassica and Raphanus genera. Only $R$. sativus emitted anisic acid methyl esters (methyl 2-methoxybenzoate and methyl 4-methoxybenzoate) and methyl nicotinate (an N-containing compound) and these accessions emitted fewer isoprenoids than the Brassica species. On the other hand, the Brassica species emitted specific aliphatics and isoprenoids that were absent from Raphanus, such as 6,10,14-trimethyl-2-pentadecanone and $(E, E)$ - $\alpha$-farnesene.

Fig. 2 is an oscillograph of the response by a honeybee's antenna toward a floral scent sample of long stalked cabbage detected by GC-EAD analysis. The responses, shown by the strong fluctuation of electrical signals in the oscillograph, to phenylacetaldehyde and 2-phenyethyl alcohol were extremely clear despite their low amount (low peak in the chromatogram). On the other hand, it to $\alpha$-pinene was unclear although the amount was more than those of former compounds. Accordingly, there might be no correlation between the amount of compound and the strength of the response by a honeybee's antenna. And because the strength of the response to each compound also slightly differed by honeybees (data not shown), only compounds shown by stably-distinct response were determined as active compounds. As results, we detected 14 active compounds, with the total number ranging from 8 to 10 for each species 
Table 2. The compositions (\% of total) of the volatile compounds identified in the floral scent of six Brassica and one Raphanus species

\begin{tabular}{|c|c|c|c|c|c|c|c|c|}
\hline \multicolumn{2}{|c|}{ Compound } & B. rapa & B. nigra & B. oleracea & B. juncea & B. napus & B. carinata & R. sativus \\
\hline \multicolumn{9}{|c|}{ Aliphatics } \\
\hline 1 & 6,10,14-Trimethyl-2-pentadecanone & 1.8 & 2.0 & 3.1 & 1.3 & 3.0 & 13.5 & - \\
\hline 2 & 2,6,10,14-Tetramethylhexadecane & 1.7 & 0.8 & 3.6 & 0.2 & 0.1 & 2.3 & - \\
\hline 3 & $13,14,15,16,17$-pentanorlabda-7,9(11)diene & - & 1.5 & - & - & - & 1.3 & - \\
\hline 4 & $(Z)-3-H e x e n-1-o l$ & 6.7 & 3.0 & 0.7 & 0.4 & 7.1 & 0.9 & 0.5 \\
\hline \multicolumn{9}{|c|}{ Aromatics } \\
\hline 5 & Benzaldehyde & 0.4 & 2.1 & - & 0.9 & - & 3.6 & - \\
\hline 6 & 2-Methoxybenzaldehyde & - & - & - & - & - & - & 0.4 \\
\hline 7 & 4-Methoxybenzaldehyde & 0.1 & 4.0 & - & - & - & 0.3 & - \\
\hline 8 & Phenylacetaldehyde & 17.4 & 2.3 & - & 9.7 & 2.9 & 2.5 & 2.6 \\
\hline 9 & 2-Phenylethyl acetate & 1.8 & 2.4 & 3.4 & 0.9 & 2.5 & 0.5 & 0.9 \\
\hline 10 & Benzyl alcohol & - & 0.5 & 2.2 & 0.3 & 0.8 & 1.3 & - \\
\hline 11 & 2-Methoxybenzyl alcohol & - & - & - & - & - & - & 0.4 \\
\hline 12 & 2-Phenylethyl alcohol & 7.2 & 2.6 & 19.5 & 2.4 & 22.3 & 11.6 & 2.0 \\
\hline 13 & Methyl salicylate & 3.4 & - & 0.3 & - & - & 0.2 & 5.5 \\
\hline 14 & Methyl phenylacetate & - & - & - & - & - & - & 2.0 \\
\hline 15 & Methyl benzoate & 1.3 & - & 9.0 & - & 0.7 & - & 1.5 \\
\hline 16 & Methyl 2-methoxybenzoate & - & - & - & - & - & - & 63.4 \\
\hline 17 & Methyl 4-methoxybenzoate & - & - & - & - & - & - & 6.7 \\
\hline 18 & Benzyl benzoate & - & 0.1 & 0.2 & - & - & - & - \\
\hline 19 & Benzyl 3-methylbutanoate & - & - & - & - & - & - & 0.5 \\
\hline 20 & Benzyl 2-methylpropanoate & - & - & - & - & - & - & 0.6 \\
\hline 21 & Benzyl tiglate & - & - & - & - & - & - & 4.1 \\
\hline 22 & Bibenzyl & - & 0.03 & - & 0.3 & - & - & - \\
\hline \multicolumn{9}{|c|}{ Isoprenoids } \\
\hline \multicolumn{9}{|c|}{ Irregular terpenes } \\
\hline \multicolumn{9}{|c|}{ Monoterpenes } \\
\hline 24 & $(E)$ - $\beta$-Ocimene & - & 33.1 & 1.0 & 66.0 & 1.3 & 12.1 & 0.1 \\
\hline 25 & (E)- $\alpha$-Ocimene & - & 0.8 & - & 1.7 & - & 0.2 & - \\
\hline 26 & $\begin{array}{l}\text { (4E,6Z)-2,6-Dimethyl-2,4,6-octatriene } \\
\text { (Neoalloocimene) }\end{array}$ & - & 0.5 & - & 0.8 & - & 0.1 & - \\
\hline 27 & $\alpha$-Pinene & - & 18.2 & - & 3.2 & - & 24.5 & - \\
\hline 28 & $\beta$-Pinene & - & 1.9 & - & 0.1 & - & 1.2 & - \\
\hline 29 & $\beta$-Myrcene & 0.3 & 4.8 & 11.3 & 0.6 & 13.9 & 2.8 & - \\
\hline 30 & Limonene & 0.1 & 0.3 & 22.1 & 1.8 & 1.9 & 4.5 & 0.1 \\
\hline 31 & Linalool & 0.2 & 0.3 & 7.3 & - & 4.8 & 1.6 & - \\
\hline 32 & Sabinene & - & 2.6 & 7.6 & 0.01 & 0.1 & 1.0 & - \\
\hline 33 & $\beta$-Phellandrene & - & 10.2 & - & 0.8 & - & 7.9 & - \\
\hline 34 & cis-Verbenol & - & 0.2 & - & - & - & 0.04 & - \\
\hline 35 & 1,8-Cineole & - & - & 0.5 & - & - & - & - \\
\hline 36 & $\delta$-3-Carene & - & - & - & - & - & - & - \\
\hline 37 & $\delta$-Germacrene & 0.5 & - & - & 0.1 & - & - & - \\
\hline \multicolumn{9}{|c|}{ Sesquiterpenes } \\
\hline 38 & $(E, E)-\alpha$-Farnesene & 38.9 & 2.9 & 5.3 & 5.7 & 30.5 & 3.1 & - \\
\hline 39 & $(Z, E)$ - $\alpha$-Farnesene & 0.6 & 0.4 & - & 0.3 & - & 0.1 & - \\
\hline 40 & Caryophyllene & 1.4 & - & - & 0.1 & 4.5 & 0.2 & - \\
\hline 41 & $\beta$-Cubebene & 1.1 & - & - & 0.2 & - & - & - \\
\hline 42 & $\beta$-Elemene & - & - & 2.8 & - & - & - & - \\
\hline 43 & $\alpha$-Muurolene & 1.0 & - & - & - & - & - & - \\
\hline 44 & $\alpha$-Guaiene & - & 1.2 & - & - & - & - & - \\
\hline 45 & $\alpha$-Gurjunene & 1.6 & 0.1 & - & 0.3 & - & - & - \\
\hline 46 & Copaene & 5.6 & - & - & 0.8 & - & - & - \\
\hline 47 & $\delta$-Cadinene & 1.2 & - & - & 0.1 & - & - & - \\
\hline \multicolumn{9}{|c|}{ Nitrogen-containing compounds } \\
\hline 48 & $1 H$-Indole & 1.2 & 0.2 & - & 0.5 & 3.5 & 1.1 & - \\
\hline 49 & 2-Aminobenzaldehyde & 1.2 & 0.5 & - & 0.1 & - & - & - \\
\hline 50 & 2-Phenylnitroethane & 2.0 & 0.1 & - & 0.3 & 0.2 & 0.7 & - \\
\hline 51 & Benzonitrile & 1.4 & 0.03 & - & 0.1 & - & 0.7 & - \\
\hline 52 & Methyl nicotinate & - & - & - & - & - & - & 8.7 \\
\hline \multicolumn{2}{|c|}{ Total $(\%)$} & 100 & 100 & 100 & 100 & 100 & 100 & 100 \\
\hline
\end{tabular}

Each value represents the arithmetic average among the cultivars or lines of each species.

Physiologically active compounds are boldfaced.

'-' means not detected. 
Table 3. Variations in the total number and amounts of compounds identified in the floral scent and the composition of the active compounds in the seven species

\begin{tabular}{|c|c|c|c|c|c|c|}
\hline \multirow{2}{*}{$\begin{array}{l}\text { Species } \\
\text { B. rapa }\end{array}$} & \multicolumn{2}{|c|}{ Total number } & \multicolumn{2}{|c|}{$\begin{array}{l}\text { Total amount per flower } \\
\left(\text { pico ampere } \times \mathrm{s} / 10^{5}\right)^{d}\end{array}$} & \multicolumn{2}{|c|}{$\begin{array}{l}\text { Ratio of the active compounds in the } \\
\text { floral scent compounds }(\%)\end{array}$} \\
\hline & $6.3 a b$ & $(5-7)$ & $4.1 b c$ & $(1.2-7.7)$ & $73.5 a$ & $(60.6-83.7)$ \\
\hline B. nigra & $6.8 a$ & $(4-8)$ & $10.4 b c$ & $(0.4-29.9)$ & $47.8 a$ & $(11.2-86.6)$ \\
\hline B. oleracea & $3.2 b$ & $(2-6)$ & $1.3 c$ & $(0.3-2.9)$ & $49.0 \quad a$ & $(26.6-72.8)$ \\
\hline B. juncea & $7.0 \quad a$ & $(6-8)$ & $14.8 a b$ & (7.6-28.2) & $87.3 a$ & $(79.5-93.2)$ \\
\hline B. napus & $5.8 a b$ & $(2-9)$ & $2.4 b c$ & $(0.8-4.1)$ & $71.4 \quad a$ & $(53.1-84.5)$ \\
\hline B. carinata & $6.0 a b$ & $(3-8)$ & $3.4 b c$ & $(0.4-13.4)$ & $49.8 a$ & $(17.1-78.9)$ \\
\hline R. sativus & $8.5 a$ & $(8-9)$ & $31.6 a$ & $(30.8-32.4)$ & $91.4 a$ & $(90.3-92.5)$ \\
\hline
\end{tabular}

$\overline{a-c}$ Values within a column labeled with different letters differ significantly among the species (Tukey's HSD test, $P<0.05$ ).

${ }^{d} \Sigma($ peak area/10 $)=\Sigma$ (peak height (pico ampere) $\times$ full width at half maximum of the peak (generated seconds) $\left./ 10^{5}\right\}$.

Ranges among the lines are shown in parentheses.

(Table 2) and from 2 to 9 for each accession (Table 3). We found active compounds that were common to the two genera such as 2-phenylethyl acetate and 2-phenylethyl alcohol and species-specific active compounds such as methyl 2-methoxybenzoate and methyl nicotinate ( $R$. sativus). $R$. sativus had the largest number and amounts of active compounds and $B$. oleracea had the fewest in both categories. The proportions of active compounds in the floral scent varied widely, ranging from $11.2 \%$ to $93.2 \%$ among accessions in the seven species and so the inter-specific difference was not significant $(P>0.05)$. These results suggest that the Brassicaceae species emit a range of compounds, not all of which attract honeybees. In addition, the number, amount and ratio of the active compounds did not differ between the diploid and amphidiploid species.

Five groups were obtained by cluster analysis using the presence or absence data for all active compounds (Fig. 3A). The overall variation was divided into two main groups based on whether a group had either methyl salicylate or methyl benzoate, both compounds, or neither compound (Table 4A). That is, group 1 had both compounds as well as various other compounds, group 5 had methyl benzoate and isoprenoids, group 4 had methyl salicylate as well as aliphatics and aromatics, group 3 had both compounds as well as many specific compounds such as anisic acid methyl esters and methyl nicotinate and group 2 lacked both compounds. Group 3 contained only the two radish accessions, whereas the other groups contained multiple Brassica species. Accessions belonging to group 5 , all had the $\mathrm{C}$ genome.

Four groups were delineated on the basis of the amount of active compounds (Fig. 3B). The overall variation was explained mainly by the amount of $(E)$ - $\beta$-ocimene (Table 4B). Some of the B. nigra and B. carinata accessions and all $B$. juncea accessions, which share the B genome, were classified into either group 2 or group 4 with much emission of $(E)$ - $\beta$-ocimene. The other groups had accessions that emitted no $(E)$ - $\beta$-ocimene, but accessions in group 3 emitted much of an anisic acid methyl ester (methyl 2methoxybenzoate) and accessions in group 1 emitted little of the active compounds. The majority of the accessions ( 22 of
32) were classified into group 1, which contained accessions with multiple genomes. The two radishes were both contained in group 3. The groups in this dendrogram were the same at the $75 \%$ and $50 \%$ similarity levels, indicating that differences among these four groups were larger than in the other clusters.

Six groups were obtained in the dendrogram based on the compositions of active compounds and their characteristics and the genome constitutions were relatively simple in each group (Fig. 3C and Table 4C). That is, accessions in group 1 had $(E, E)-\alpha$-farnesene as the major component and contained mainly accessions with the A genome. Group 2 had $(E)$ - $\beta$-ocimene as the major component and contained accessions with the B genome. Group 4 had accessions with methyl benzoate and linalool as the major components and contained only B. oleracea. Group 5 had accessions with 2phenylethyl alcohol as the major component and contained accessions with the $\mathrm{C}$ genome. Group 3 had no major components and contained accessions with the $\mathrm{B}$ genome. Group 6 had methyl 2-methoxybenzoate as its major component, and included only the two radishes. The three diploid species were mainly classified into different groups and the amphidiploid species were placed with their ancestral species. In the clusters based on the presence or absence data and the amount of active compounds, most groups included species with multiple genomes, but each group had a distinctly different genome in the composition cluster.

\section{Discussion}

Although the reproductive system has changed during the evolution from diploid to amphidiploid in the Brassicaceae species (Tsunoda et al. 1980), we expected that the pollinator requirement may have been maintained. In this study, qualitative and quantitative variations in the floral scent compounds recognized by a honeybee's antenna were evaluated in six Brassica species and two radish accessions. Thus far, floral scent compounds in cruciferous species have been studied from the perspectives of feeding or oviposition behavior by insects such as a cabbage weevil (Ceutorhynchus 
A

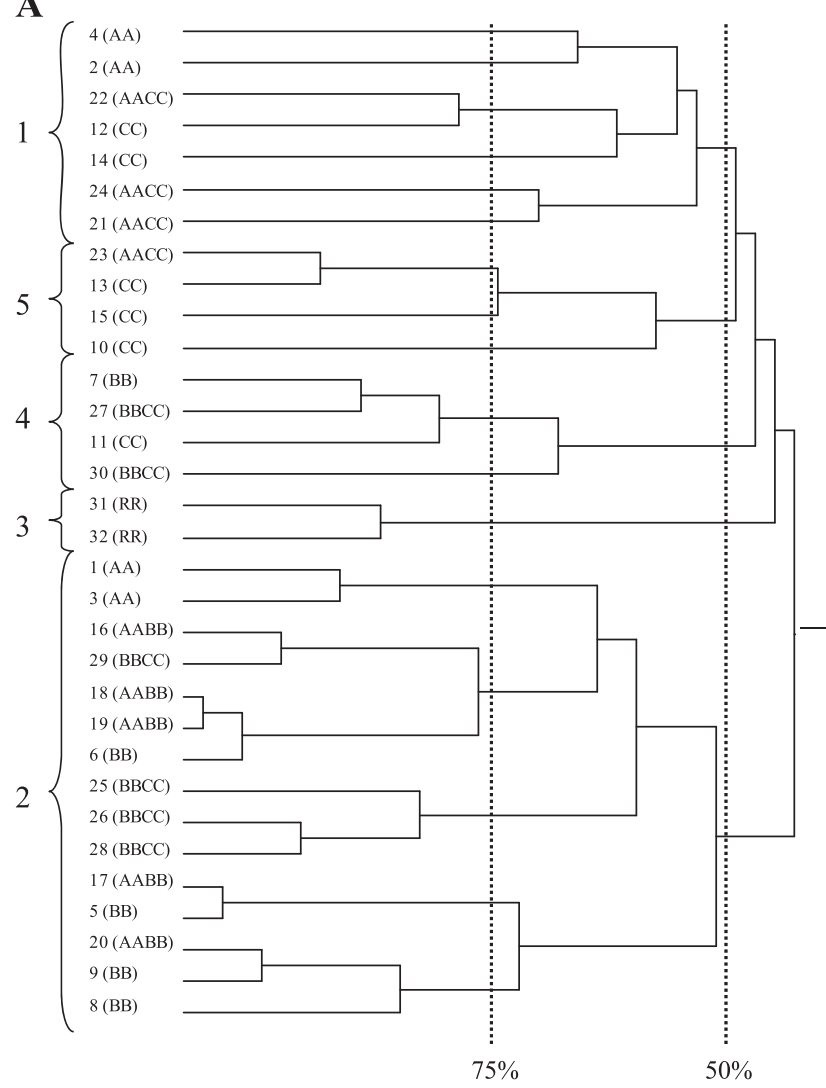

B

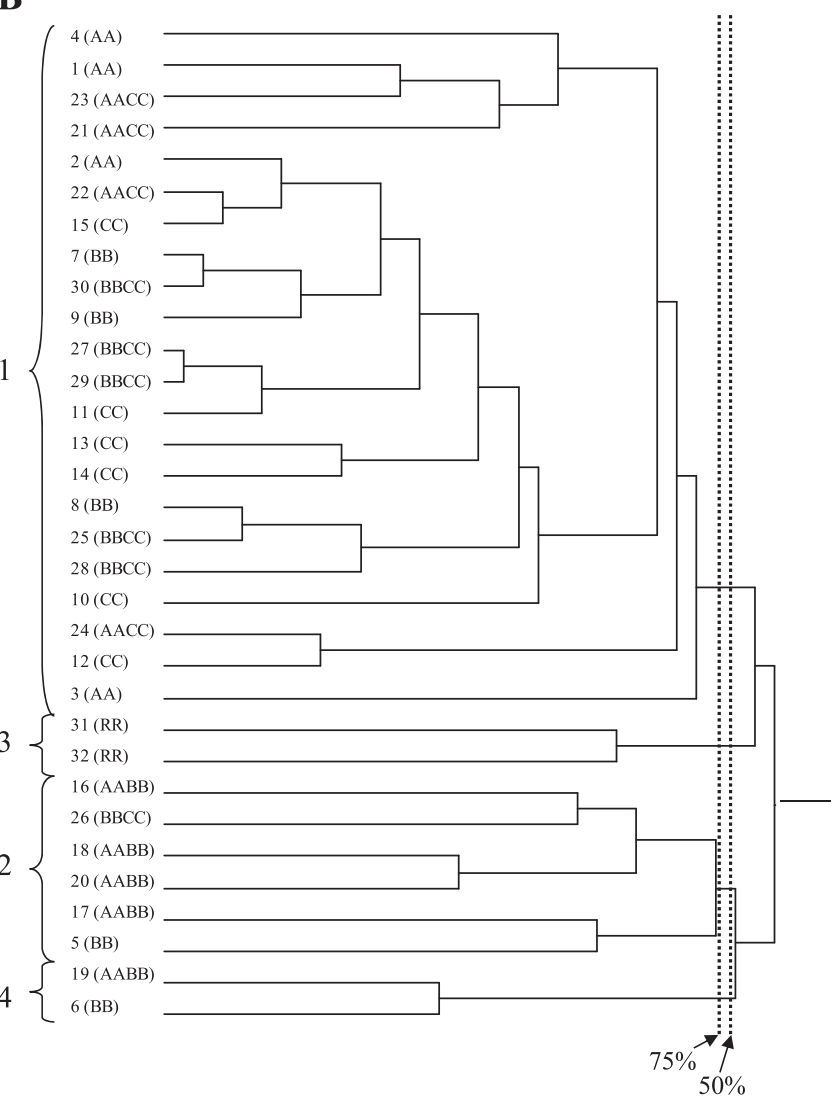

C

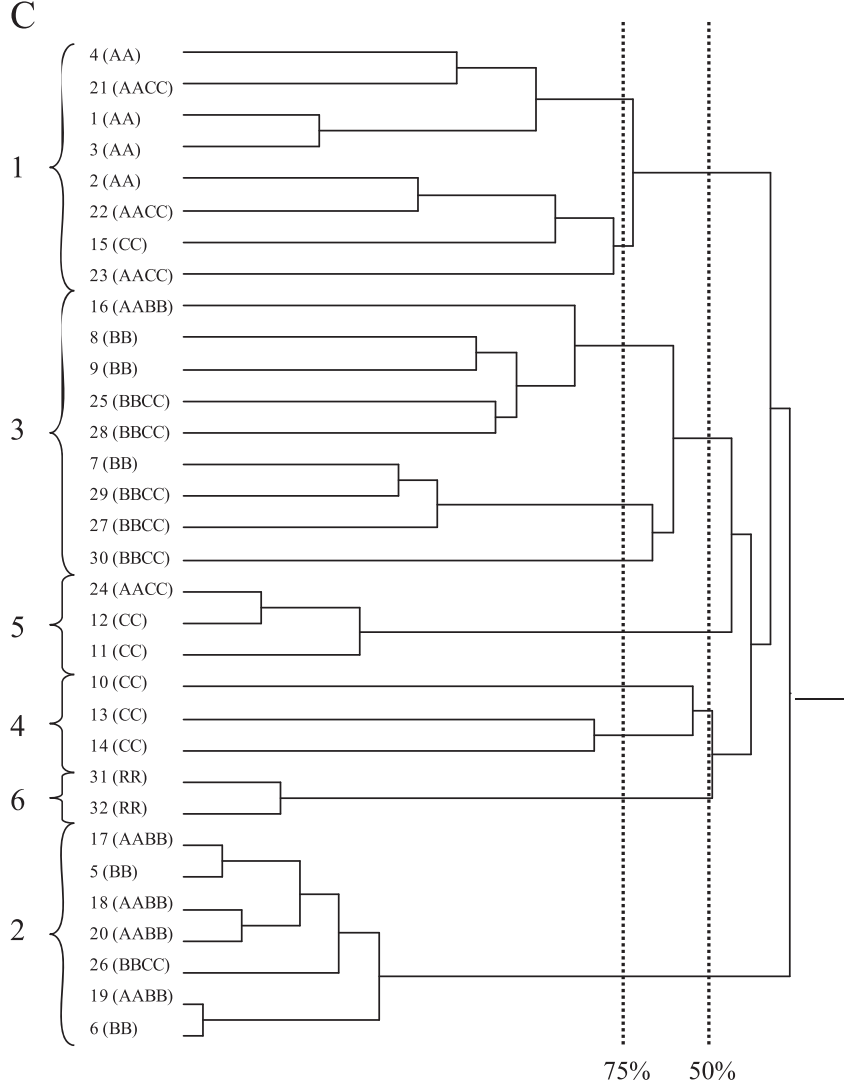

assimilis; Evans and Allen-Williams 1992) and a butterfly (Pieris rapae; Omura et al. 1999), but not from the perspective of the pollination system. A flower-pollinator system generally has a complex and mutualistic interaction and the pollinators' foraging behavior would be influenced by morphological and optical cues and learning as well as odor cues (Chittka and Raine 2006). And, many kinds of insects visit the Brassicaceae flowers as pollinators. However, it is worthwhile to evaluate the floral scent variation from the viewpoint of honeybees, which are one of the main pollinator, for deeply understanding of the reproductive system in the Brassicaceae species.

Of the 52 compounds detected in the floral scent, 14 produced clear responses in the antennae of the bees (Table 2). All species had at least two compounds (Table 3). And although there were significant differences in the number and amounts of the active compounds among species, the ranges within each species were wide and overlapped among the species. Therefore, all seven species appear to require a

Fig. 3. Dendrograms produced by cluster analysis based on (A) presence or absence, (B) amount (peak area per flower) and (C) composition (\%) of all active compounds in the 32 Brassicaceae accessions. The accession numbers (and their genome, in parentheses) correspond to the numbers in Table 1. The two dashed lines indicate separation points at $50 \%$ and $75 \%$ similarity. The four to six groups were separated at the $50 \%$ similarity level and the group number is shown on the left of the dendrogram. 
Table 4. Characteristic of each group clustered using (A) presence or absence, (B) amount (peak area per flower) and (C) composition (\%) of all active compounds. Compound numbers correspond to the numbers in Table 2. Values represent the arithmetic average among the accessions belonging to a given group. '-' means not detected

(A) presence or absence (frequency)

\begin{tabular}{llcrrrr}
\hline \hline \multicolumn{1}{c}{ Group number } & 1 & 2 & 3 & 4 & 5 \\
(Number of accessions in each group) & $(7)$ & $(15)$ & $(2)$ & $(4)$ & $(4)$ \\
\hline 1 & 6,10,14-Trimethyl-2-pentadecanone & 0.7 & 0.9 & - & 1.0 & - \\
5 & Benzaldehyde & 0.1 & 1.0 & - & 0.8 & - \\
8 & Phenylacetaldehyde & 0.4 & 0.9 & 1.0 & - & - \\
9 & 2-Phenylethyl acetate & 0.6 & 0.3 & 1.0 & 0.5 & 0.5 \\
12 & 2-Phenylethyl alcohol & 0.9 & 1.0 & 1.0 & 0.8 & - \\
13 & Methyl salicylate & 0.4 & - & 1.0 & 0.3 & - \\
15 & Methyl benzoate & 0.7 & - & 1.0 & - & 0.3 \\
16 & Methyl 2-methoxybenzoate & - & - & 1.0 & - & - \\
17 & Methyl 4-methoxybenzoate & - & - & 1.0 & - & - \\
24 & (E)- $\beta-O c i m e n e$ & 0.4 & 0.9 & 0.5 & - & 0.3 \\
31 & Linalool & 0.9 & 0.3 & - & - & 0.5 \\
38 & (E,E)- $\alpha-F a r n e s e n e$ & 1.0 & 1.0 & - & - & 0.8 \\
48 & 1H-Indole & 0.3 & 0.7 & - & - & - \\
52 & Methyl nicotinate & - & - & 1.0 & - & - \\
\hline Total & 6.4 & 7.0 & 8.5 & 3.3 & 2.3 \\
\hline
\end{tabular}

(B) amount (pico ampere $\times \mathrm{s} / 10^{5}$ )

\begin{tabular}{|c|c|c|c|c|c|}
\hline \multicolumn{2}{|r|}{$\begin{array}{c}\text { Group number } \\
\text { (Number of accessions in each group) }\end{array}$} & \multirow{2}{*}{$\begin{array}{c}1 \\
(22) \\
0.11\end{array}$} & \multirow{2}{*}{$\begin{array}{c}2 \\
(6) \\
0.13\end{array}$} & \multirow{2}{*}{$\begin{array}{c}3 \\
(2) \\
\end{array}$} & \multirow{2}{*}{$\begin{array}{c}4 \\
(2) \\
0.19\end{array}$} \\
\hline 1 & 6,10,14-Trimethyl-2-pentadecanone & & & & \\
\hline 5 & Benzaldehyde & 0.05 & 0.16 & - & 0.16 \\
\hline 8 & Phenylacetaldehyde & 0.30 & 0.92 & 1.03 & 1.44 \\
\hline 9 & 2-Pher & 0.07 & 0.09 & 0.33 & \\
\hline 12 & 2-Phe & 0.44 & 0.35 & 0.76 & 0.38 \\
\hline 13 & Methyl salicy & 0.02 & - & 2.16 & \\
\hline 15 & Methyl benzoate & 0.10 & - & 0.56 & \\
\hline 16 & Methyl 2-methoxybenzoate & - & - & 21.59 & \\
\hline & Methyl 4-methoxybenzoate & - & - & 2.16 & \\
\hline 24 & (E)- $\beta$-Ocimene & 0.15 & 10.30 & 0.03 & 25.92 \\
\hline & Linalool & 0.11 & 0.10 & - & \\
\hline & (E,E)- $\alpha$-Farnesene & 0.56 & 0.86 & - & 0.71 \\
\hline & 1H-Indole & 0.06 & 0.13 & - & 0.29 \\
\hline & Methyl nicotinate & - & - & 2.99 & \\
\hline Tot & & 1.98 & 13.04 & 31.61 & 29.0 \\
\hline
\end{tabular}

(C) composition (\%)

\begin{tabular}{|c|c|c|c|c|c|c|}
\hline $\begin{array}{l}\text { Group number (Number of } \\
\text { accessions in each group) }\end{array}$ & $\begin{array}{c}1 \\
(8)\end{array}$ & $\begin{array}{c}2 \\
(7)\end{array}$ & $\begin{array}{c}3 \\
(9)\end{array}$ & $\begin{array}{c}4 \\
(3)\end{array}$ & $\begin{array}{c}5 \\
(3)\end{array}$ & $\begin{array}{c}6 \\
(2)\end{array}$ \\
\hline 1 6,10,14-Trimethyl-2-pentadecanone & 4.0 & 1.3 & 25.8 & 0.7 & 8.2 & - \\
\hline 5 Benzaldehyde & 0.3 & 1.3 & 10.0 & - & - & - \\
\hline 8 Phenylacetaldehyde & 13.6 & 4.7 & 8.1 & - & - & 2.9 \\
\hline 9 2-Phenylethyl acetate & 8.8 & 1.0 & 7.2 & 4.7 & 0.6 & 1.0 \\
\hline 12 2-Phenylethyl alcohol & 10.1 & 2.4 & 21.1 & - & 81.1 & 2.3 \\
\hline 13 Methyl salicylate & 2.0 & - & 0.6 & 1.6 & - & 6.2 \\
\hline 15 Methyl benzoate & 1.7 & - & - & 39.0 & - & 1.7 \\
\hline 16 Methyl 2-methoxybenzoate & - & - & - & - & - & 69.1 \\
\hline 17 Methyl 4-methoxybenzoate & - & - & - & - & - & 7.3 \\
\hline 24 (E)- $\beta$-Ocimene & 0.4 & 81.1 & 20.1 & 4.4 & 1.2 & 0.1 \\
\hline 31 Linalool & 3.6 & 0.7 & 2.5 & 42.1 & 2.4 & - \\
\hline 38 (E,E)- $\alpha$-Farnesene & 52.9 & 6.3 & 3.6 & 7.4 & 5.2 & - \\
\hline 48 1H-Indole & 2.6 & 1.0 & 1.0 & - & 1.3 & - \\
\hline 52 Methyl nicotinate & - & - & - & - & - & 9.5 \\
\hline Total & 100.0 & 100.0 & 100.0 & 100.0 & 100.0 & 100.0 \\
\hline
\end{tabular}

pollinator's assistance to reproduce, and their floral scents would be essential secondary metabolic products to attract pollinators and increase the likelihood of successful reproduction whether its reproductive system is self-incompatible or self-compatible. But the production mechanism would be different between Brassica and Raphanus genera since the radishes emitted different compounds and consistently formed a separate group from Brassica species in the cluster analyses (Table 2 and Fig. 3A-3C).

The six Brassica species were divided into three to five groups in cluster analyses of the presence or absence, amount and composition of the active compounds, indicating both qualitative and quantitative variations in the active compounds (Fig. 3A-3C). Except for group 4 in the composition cluster, which contained only diploid accessions with the CC genome, each group contained both diploid and amphidiploid species with the same genome in all three clusters. Therefore, the variations in the active compounds appear to depend not on the species, but on the genome. Especially, the composition cluster most clearly reflected the genome constitution in the Brassica species (Fig. 3C). The three species with different genomes (B. rapa, B. nigra and $B$. oleracea) were mostly separated into different groups. B. juncea and B. carinata accessions, which had the B genome, were in the same group as their ancestral $B$. nigra and most B. napus accessions, which had the A genome, were in the same group as their ancestral B. rapa. From these results, the composition of the active compounds would depend on the genome constitution and its genetic basis might have been maintained in each genome. There are several pathways for the biochemical synthesis of floral scent compounds and the enzymes and genes that control these processes in each pathway have become clearer (Dudareva and Pichersky 2000). The active compounds shown in this study (Table 2) are synthesized by several different pathways such as aromatics and terpenes (Dudareva and Pichersky 2000, Yamaoka and Miyake 1999). Our result will support the existence of integrative genes that govern the expression of the genes responsible for each synthesis pathway (Wright et al. 2005). Another two clusters show unique features. In the presence or absence cluster, two types of genome species were contained in the some groups (Fig. 3A). This result suggests that highly common compounds among genomes would also be utilized as active compounds as well as genome-specific compounds. In the amount cluster, some B. nigra and B. carinata accessions and all $B$. juncea accessions, which share the B genome, emitted large amounts of $(E)$ - $\beta$-ocimene, yet most accessions were included in group 1, irrespective of their genome (Fig. 3B), suggesting that the variation in the amount of active compounds was mainly explained by $(E)-\beta$-ocimene and there would be little difference among accessions in the amount variation except $(E)-\beta$-ocimene. While the more groups were created at $75 \%$ similarity level than those at $50 \%$ similarity level in the presence or absence and composition clusters (Fig. 3A, 3C), the same three groups at 50\% 
similarity level were also created at $75 \%$ similarity level in the amount cluster. Therefore, it can be said that differences among the groups at $50 \%$ similarity level in the emission amount are greater compared to those in the presence or absence and composition of the active compounds.

As mentioned above, we could find qualitative and quantitative variation in the active compounds. Insect pollinators including honeybees recognize such active compounds but do not always utilize them for foraging (Yamaoka and Miyake 1999). However, 2-phenylethyl acetate, 2phenylethyl alcohol and $(E, E)$ - $\alpha$-farnesene, which we detected here, produce strong physiological or behavioral responses from a cabbage butterfly ( $P$. rapae; Omura et al. (1999), a cabbage seed weevil (C. assimilis; Evans and Allen-Williams 1992) and another butterfly (Heliconius melpomene; Andersson and Dobson 2003). Although these insects utilize the Brassicaceae flowers for feeding or oviposition, these previous reports suggest that compounds inducing or related to foraging behavior of honeybees would be present among the active compounds. To identify the key compounds, its amount, or specific composition of the key compounds utilized for foraging by honeybees from the 14 active compounds, it will be necessary to investigate honeybee's behavior towards each compound, amount and composition by bioassays using a wind tunnel or field experiment. In the GC-EAD analysis, honeybees in the same colony were used. Because strength of the response to each compound slightly differed by individuals (data not shown), there is a possibility that the responsiveness to each compounds differs by colonies as well as individuals within colony. In addition, because many kinds of insects visit the flowers as pollinators, experiments considering the diversity on the part of insect pollinators should be needed in the future.

Honeybees are widely used as the pollinator in commercial seed production of Brassicaceae crops owing to their high pollination efficiency (Kobayashi et al. 2010). From the view point of commercial seed production, it was valuable to identify the active compounds detected by honeybees and to explore their qualitative and quantitative variations. In $B$. rapa and $B$. oleracea, in which $\mathrm{F}_{1}$ seed production is concentrated, all accessions were in group 1 in the amount cluster, but were spread among different groups in the presence or absence and composition clusters (Fig. 3A-3C). Therefore, it might be expected that there is little difference among accessions in the amount, but in the presence or absence and composition of the active compounds. In addition, the compounds emitted by the two radishes differed greatly from those emitted by the Brassica species. Different pollinator visitation frequencies between these two genera and between accessions belonging to the same species have been reported (Free 1970, Kobayashi et al. 2010). Because insect pollinators can recognize the differences in presence or absence of specific compounds and composition of several compounds (Barth 1993, Huber et al. 2005, Omura et al. 1999), these inter-genus or intra-specific variations and fur- ther detailed variation might be utilized by pollinators, resulted in the different visitation frequencies. Although we could not find intra-specific variation in $R$. sativus in this study, to examine the relationship between the variation in floral scent in R. sativus and pollinators' behavior, analysis using more accessions will be needed. Because our results suggest that the qualitative and quantitative variation have a genetic basis, clarifying the relationship between the floral scent and pollinator behavior might make it possible to control pollinator visitation by genetically modifying the floral scent, leading to greater seed production.

\section{Acknowledgments}

We thank Tohoku University, Utsunomiya University, the NIAS Genebank and the Tohoku Seed Company for providing the plant materials. This work was supported by a grant for a Research Project for Utilizing Advanced Technology in Agriculture, Forestry and Fisheries from the Ministry of Agriculture, Forestry and Fisheries of Japan (1655, 20042007) and by a KAKENHI Grant-in-Aid for Scientific Research (15658003).

\section{Literature Cited}

Ai,H., K. Kuwasawa, T.Yazawa, M.Kurokawa, M.Shimoda and K. Kiguchi (1995) A physiological saline for Lepidopterous insects: effects of ionic composition on heart beat and neuromuscular transmission. J. Insect Physiol. 41: 571-580.

Andersson,S. and H.E.M.Dobson (2003) Antennal responses to floral scents in the butterfly Heliconius melpomene. J. Chem. Ecol. 29: 2319-2330.

Barth,F.G. (1997) Biologie einer begegnung die partnerschaft der insekten und blumen (titled "Insect and flower", translated by Shibuya, T.). Yasaka Syobo, Tokyo, p. 392.

Chittka,L. and N.E. Raine (2006) Recognition of flowers by pollinators. Curr. Opin. Plant Biol. 9: 428-435.

Dudareva, N. and E.Pichersky (2000) Biochemical and molecular genetic aspects of floral scent. Plant Physiol. 122: 627-633.

Evans, K.A. and L.J.Allen-Williams (1992) Electroantennogram responses of the cabbage seed weevil, Ceutorhynchus assimilis, to oilseed rape, Brassica napus ssp. oleifera, volatiles. J. Chem. Ecol. 18: 1641-1659.

Free,J.B. (1970) Insect pollination of crops. Academic Press Inc., New York, p. 544.

Free,J.B. and Y.Spencer-Booth (1963) The pollination of mustard by honeybees. J. Apic. Res. 2: 69-70.

Free, J.B. and P.M.Nuttall (1968) The pollination of oilseed rape (Brassica napus) and the behavior of bees on the crop. J. Agric. Sci. 71: 91-94.

Huber,F.K., R.Kaiser, W.Sauter and F.P.Schiestl (2005) Floral scent emission and pollinator attraction in two species of Gymnadenia (Orchidaceae). Oecologia 142: 564-575.

Jakobsen,H.B., P.Friis, J.K.Nielsen and C.E.Olsen (1994) Emission of volatiles from flowers and leaves of Brassica napus in situ. Phytochemistry 37: 695-699.

Jenkinson,J.G. and G.D.Glynne-Jones (1953) Observations on the pollination of oil rape and broccoli (Brassica napus and B. oleracea). Bee World 34: 173-177. 
Kobayashi,K., S.Tsukamoto, A.Tanaka, S.Niikura and R.Ohsawa (2010) Selective flower visitation behavior by pollinators in a radish $\mathrm{F}_{1}$ seed production field. Breed. Sci. 60: 203-211.

Niikura, S. (2007) Genetic analysis of reproductive characteristics for the breeding of cruciferous vegetables. Breed. Res. 9:153-160.

Ohsawa, R. and H.Namai (1987) The effect of insect pollinators on pollination and seed setting in Brassica campestris cv. Nozawana and B. juncea cv. Kikarashina. Jpn. J. Breed. 37: 453-463.

Omura,H., K.Honda and N.Hayashi (1999) Chemical and chromatic bases for preferential visiting by the cabbage butterfly, Pieris rapae, to rape flowers. J. Chem. Ecol. 25: 1895-1906.

Pratap,A. and S.K.Gupta (2009) Biology and ecology of wild crucifers. In: Gupta,S.K. (ed.) Biology and Breeding of Crucifers, CRC Press, New York, pp. 37-67.

Robertson, G.W. (1993) The application of thermal desorption gas chromatography-mass spectrometry to the analyses of flower volatiles from five varieties of oilseed rape (Brassica napus spp. oleifera). Phytochem. Anal. 4: 152-157.

Sneath,P.H.A. and R.R. Sokal (1994) Classification structure. In Nishida, H. and T. Sato (eds.) Numerical taxonomy, Uchida Rokakuho Publishing Co., Ltd., Tokyo, pp. 217-356.

Struble,D.L. and H.Arn (1984) Combined gas chromatography and electroantennogram recording of insect olfactory responses. In: Hummel,H.E. and T.A.Millar (eds.) Techniques in Pheromone Research, Springer-Verlag, New York, pp. 161-178.

Tanaka,A., A.Konuma, T.Hara, A.Horisaki, S.Niikura and R.Ohsawa (2007) Evaluation of floral preference by honeybees. Abstracts of the 54th Annual Meeting of the Ecological Society of Japan: 345.

Tollsten,L. and G.Bergström (1988) Headspace volatiles of whole plants and macerated plant parts of Brassica and Sinapis. Phytochemistry 27: 4013-4018.

Tsunoda, S., K.Hinata and C.Gomez-Campo (1980) Brassica Crops and Wild Allies. Japan Scientific Societies Press, Tokyo, p. 354.

Warwick, S.I., A.Francis and I.A.Al-Shehbaz (2006) Brassicaceae: species checklist and database on CD-ROM. Pl. Syst. Evol. 259: 249-258.

Wright, G.A., A.Lutmerding, N.Dudareva and B.H.Smith (2005) Intensity and the ratios of compounds in the scent of snapdragon flowers affect scent discrimination by honeybees (Apis mellifera). J. Comp. Physiol. A. 191: 105-114.

Yamaoka,R. and T.Miyake (1999) Chemical ecology in floral scents. In: Ohara, M. (ed.) Natural History of Flowers, University of Hokkaido, Sapporo, pp. 89-103. 